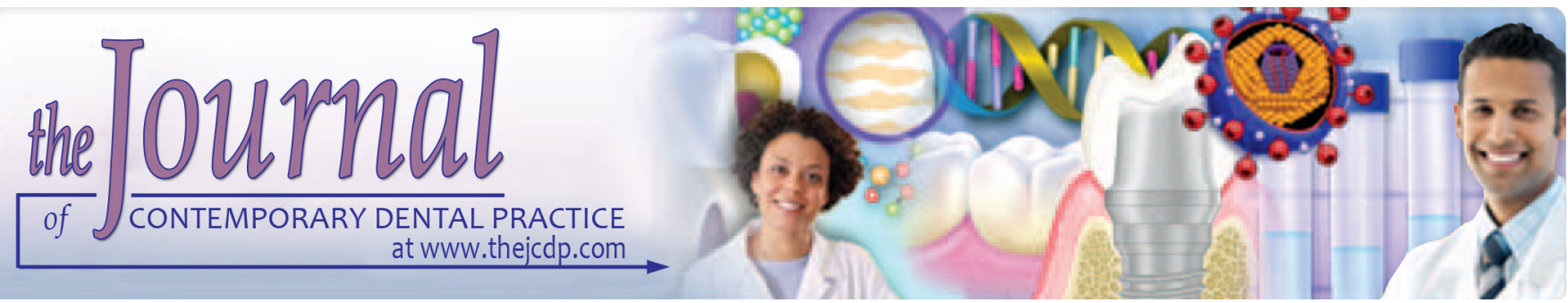

\title{
Comparative Evaluation of Different Bone Markers in Peri-implant Crevicular Fluid of Immediate Loaded and Nonloaded Dental Implants
}

\author{
${ }^{1}$ Md Imran UI Haque, ${ }^{2}$ Puneet Sharma, ${ }^{3}$ Aditya Tiwari , ${ }^{4}$ Sambit Subhas, ${ }^{5}$ Manu Rana, ${ }^{6}$ Vaibhav Kumar
}

\begin{abstract}
Aim: The present study was conducted to determine different bone markers in immediate loaded and nonloaded dental implants.

Materials and methods: It comprised of 60 patients (males-30, females-30) which were divided into two groups of 30 each. Group, I received immediate loaded dental implants, and group II received non-loaded dental implants. Modified bleeding on probing index, peri-implant sulcus depth was assessed in both groups at 1 month, 2 months, 3 months and 4 months. The crevicular fluid was obtained to determine bone markers levels such as transforming growth factor-alpha (TGF- $\alpha$ ), osteocalcin $(\mathrm{OCN})$, osteopontin (OPN), parathyroid hormone $(\mathrm{PTH})$ and osteoprotegerin (OPG).
\end{abstract}

Results: Both groups revealed non- significant difference in modified bleeding on probing index and peri-implant sulcus depth ( $p$ >0.05). Bone markers found to be elevated more in group I as compared to group II. However, the difference was non- significant $(p>0.05)$.

Conclusion: Transforming growth factor alpha (TGF- $\alpha$ ), OCN, OPN, OPG and PTH and parathyroid hormone (PTH)

\footnotetext{
${ }^{1}$ Department of Prosthodontics, SB Patil Dental College and Hospital, Bidar, Karnataka, India

${ }^{2}$ Department of Periodontics and Oral Implantology, JCD Dental College, Sirsa, Haryana, India

${ }^{3}$ Private Practitioner, Neeta Dental Health Care, Surat, Gujarat, India

${ }^{4}$ Department of Prosthodontics, Awadh Dental College and Hospital Tatanagar, Jamshedpur, Jharkhand, India

${ }^{5}$ Department of Conservative Dentistry And Endodontics, College of Medical Sciences, Bharatpur, Nepal.

${ }^{6}$ Department of Public Health Dentistry, Terna Dental College, Nerul, Navi Mumbai, Maharashtra, India

Corresponding Author: Vaibhav Kumar, Department of Public Health Dentistry, Terna Dental College, Nerul, Navi Mumbai, Maharashtra, India, Phone: +919501544877, e-mail:webs.k@ hotmail.com
}

levels were higher in immediate loaded dental implants as compared to nonloaded dental implants.

Clinical significance: Immediate loaded dental implants showed an increase in expression of bone markers such as TNF- $\alpha$, OCN, OPN, PTH and OPG which may be useful in deciding future of immediate loaded dental implants.

Keywords: Bone markers, Crevicular fluid, Immediate loaded dental implants.

How to cite this article: Haque MIU, Sharma P, Tiwari A, Subhas S, Rana M, Kumar V. Comparative Evaluation of Different Bone Markers in Peri-implant Crevicular Fluid of Immediate Loaded and Nonloaded Dental Implants. J Contemp Dent Pract 2018;19(11):1341-1345.

Source of support: Nil

Conflict of interest: None

\section{INTRODUCTION}

Dental implants are considered as one of the best options for replacing missing teeth. The aim of any replacement therapy is to achieve esthetics and function with maximum success rate. Once dental implants are inserted in bone, they unite by osseointegration. Better the osseointegration, higher will be the survival rate. ${ }^{1}$ Few studies have recommended that at least 3 months healing period for complete osseointegration is needed before placing prosthetic parts. This carries high risk of patient loss during this period. Considering this, immediate loaded dental implants emerged in dentistry which minimizes waiting period and healing time. In this technique, prosthetic part is given immediately once the implant is inserted in patient's mouth. With this, there are higher psychological benefits to the patients. Moreover, the function is restored shortly. Chiapasco et al. ${ }^{2}$ found $91.6 \%$ success rate in immediate loaded implant supported overdenture. With immediate implant supported overdenture or implant with the 
prosthetic part, patient satisfaction level has significantly improved.

Numerous studies have conducted so far depicting higher success and survival rate of immediate loaded dental implants. ${ }^{3,4}$ Branemark et al. ${ }^{5}$ in their study found that immediate loaded dental implants in the edentulous area can lead to early osseointegration. Ogawa et al. ${ }^{6}$ suggested that osseointegration is the outcome of minerals deposition around dental implants.

The present study was conducted to compare the different bone markers in peri-implant crevicular fluid of immediately loaded and non- loaded dental implants.

\section{MATERIALS AND METHODS}

The present study was conducted in the Department of Prosthodontics. It comprised 60 patients (males-30, females-30) of the age range of 20 to 60 years of both genders. All were informed regarding the study, and written consent was obtained. Ethical clearance was obtained from an institutional ethical committee. The completely edentulous patient's requiring dental implants having at least 6 months history of tooth extraction with good oral hygiene were included in the study. Patients on anti-inflammatory drugs, history of diabetes mellitus (DM), osteoporosis, hyperthyroidism, hypothyroidism, and bone graft were excluded from the study. Smokers and pregnant women were also not considered.

General information such as name, age, gender, etc. was also recorded. Patients were randomly divided into two groups of 30 each depending upon the type of treatment required. Group I was those patients who (immediately loaded implants) underwent insertion of dental implants and prosthesis within 4 days. Group II patients underwent insertion of dental implants in the first stage and prosthetic parts after 4 months in a later stage.

Dental implants were inserted following standardized aseptic surgical procedure guidelines. Before insertion, the area was anesthetized with $2 \%$ lignocaine with 1:150000 adrenaline and the mucoperiosteum was elevated. In all patients, 4 dental implants (MISS) were given in the maxillary arch and 4 in the mandibular arch. Polyglactin 6 to 10 resorbable sutures were used for suturing. All were prescribed, capsule amoxicillin $500 \mathrm{mg}$ three times a day for 5 days, tablet diclofenac sodium 50 mg three times a day for 5 days and $0.12 \%$ chlorhexidine mouthwash twice a day for a week.

A regular follow-up of patients were carried out after 1 to 4 months. In all patients, peri-implant sulcus depth (PISD) was measured using William graduated periodontal probe. Modified bleeding on probing index $(\mathrm{MBOP})$ was measured and the score was recorded. All the measurements were performed at 4 points at mesiobuccal, distobuccal, mesiolingual and distolingual sites.

For analysis of bone markers such as TGF- $\alpha, \mathrm{OCN}$, OPN, PTH and OPG, peri-implant crevicular fluid was obtained with absorbent paper points inserted at 4 sites for 30 seconds and the amount of fluid was calculated $(\mathrm{pg} / \mathrm{mL})$ using periotron and conditioned in 4 separate tubes. The fluid was collected immediately after implant insertion, after 1 week, 15 days, after 1 to 4 months. The five-parameter polynomial curve was used for determination of level. Results thus obtained were subjected to statistical analysis using Chi-square test. A p-value less than 0.05 was considered significant.

\section{RESULTS}

Mean age in group I was $54.2 \pm 4.6$ years and $55.4 \pm 5.1$ years in group II. There were $6.24 \pm 5.2$ and $5.9 \pm 5.4$ teeth in opposite arch in groups I and II respectively. In group I, $1.42 \mathrm{~mm}$ and in group II, $1.38 \mathrm{~mm}$ bone loss was observed. The difference was nonsignificant ( $p>0.05$ ) (Table 1). Mean peri-implant sulcus depth at 1 month was $3.4 \pm 0.5$ and $3.2 \pm 0.4$ in groups I and II respectively. At 2 months, it was $2.5 \pm 0.4$ in group I and $2.7 \pm 0.3$ in group II. At 3 months, it attained $2.3 \pm 0.2$ and $2.4 \pm 0.1$ levels in groups I and II respectively. At 4 months, it decreased to $2.0 \pm 0.1$ in group I and $2.2 \pm 0.1$ in group II. The difference between groups I and II was non-significant ( $p>0.05$ ) (Table 2). Mean modified bleeding on probing index at 1 month was 51.2 and 65.4, at 2 months was 7.5 and 22.8, at 3 months was 14.1 and 21.4 and at 4 months was 6.8 and 6.7 in group I and in group II respectively. The difference was non- significant ( $p>0.05$ ) (Table 3).

The TGF- $\alpha$ level at 7 th day in group I $(10 \mathrm{pg} / \mathrm{mL})$ and group II $(8 \mathrm{pg} / \mathrm{mL})$ was nonsignificant $(\mathrm{p}>0.05)$. On the 15th day, the level increased to $72 \mathrm{pg} / \mathrm{mL}$ in group I as compared to $12 \mathrm{pg} / \mathrm{mL}$ in group II which was statistically significant $(\mathrm{p}<0.05)$. On the 30th day, the level decreased to $41 \mathrm{pg} / \mathrm{mL}$ in group I, and in group II it raised to $17 \mathrm{pg} / \mathrm{mL}$. On the 60th day, it was $30 \mathrm{pg} / \mathrm{mL}$ in group I and $78 \mathrm{pg} / \mathrm{mL}$ in group II. On the 90th day, in group I, it was $22 \mathrm{pg} / \mathrm{mL}$ and in group II $76 \mathrm{pg} / \mathrm{mL}$ whereas it attained 18 $\mathrm{pg} / \mathrm{mL}$ and $38 \mathrm{pg} / \mathrm{mL}$ level in groups I and II respectively. The difference was significant $(\mathrm{p}<0.05)$ (Graph I). The level of OCN has significant difference in both groups at 15 th day, 30th day, 60th day, 90th day and 120 th day $(\mathrm{p}<0.05)$ (Graph 2). Levels of OPN have shown a significant difference at 30th day, 60th day, and 90th day in both groups $(p<0.05)(G r a p h 3)$. Level of PTH has shown a significant difference at 60th day and 90th day in both groups $(\mathrm{p}<0.05)$ (Graph 4). Similarly, OPG level increased from 15 th day to 60 th day and then decreased afterward (Graph 5). 
Table 1: Demographic data of patients

\begin{tabular}{llll}
\hline Parameters & Group I & Group II & $p$-value \\
\hline Mean age & $54.2 \pm 4.6$ & $55.4 \pm 5.1$ & 0.7 \\
M:F ratio & $1: 1$ & $1: 1$ & 1 \\
Number of teeth in antagonist arch & $6.24 \pm 5.2$ & $5.9 \pm 5.4$ & 0.41 \\
Bone loss of adjacent teeth radiographically $(\mathrm{mm})$ & 1.42 & 1.38 & 0.1 \\
\hline
\end{tabular}

Table 2: Peri-implant sulcus depth and modified bleeding on probing index in both groups

\begin{tabular}{llll}
\hline Duration & Group I (mean, $\mathrm{mm})$ & Group II (mean, $\mathrm{mm})$ & p-value \\
\hline 1 month & $3.4 \pm 0.5$ & $3.2 \pm 0.4$ & 0.5 \\
2 months & $2.5 \pm 0.4$ & $2.7 \pm 0.3$ & 0.1 \\
3 months & $2.3 \pm 0.2$ & $2.4 \pm 0.1$ & 0.41 \\
4 months & $2.0 \pm 0.1$ & $2.2 \pm 0.1$ & 0.5 \\
\hline
\end{tabular}

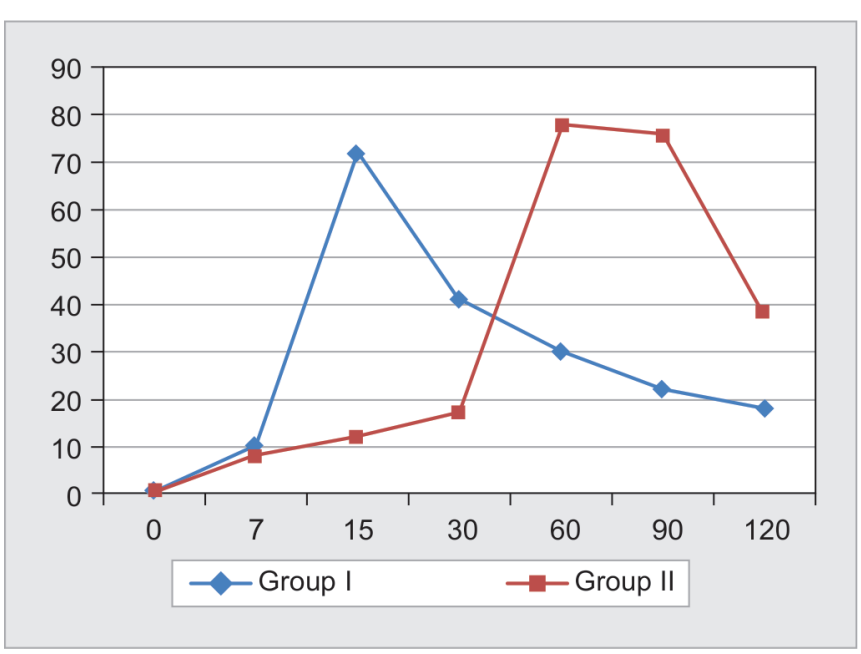

Graph 1: Level of transforming growth factor a (TGF- $\alpha$ ) in both groups

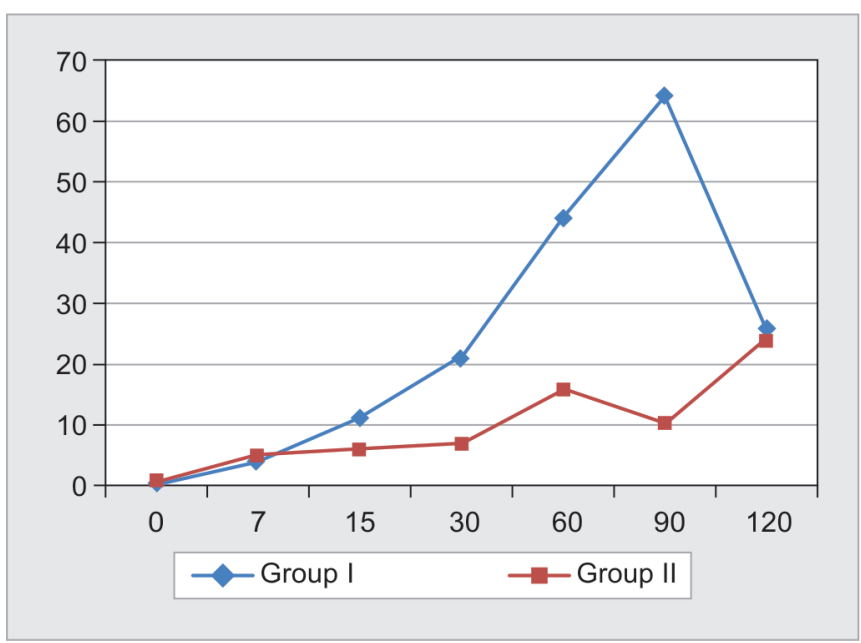

Graph 3: Level of Osteopontin (OPN) in both groups

\section{DISCUSSION}

Bone markers show variation in their levels following immediate insertion of dental implants. They play an imperative role in the process of osseointegration. Several studies have been documented in literature revealing the impact of immediately loaded implants on
Table 3: Modified bleeding on probing index in both groups

\begin{tabular}{llll}
\hline Duration & Group I (\%) & Group II (\%) & p-value \\
\hline 1 month & 51.2 & 65.4 & 0.07 \\
2 months & 7.5 & 22.8 & 0.06 \\
3 months & 14.1 & 21.4 & 0.5 \\
4 months & 6.8 & 6.7 & 1 \\
\hline
\end{tabular}

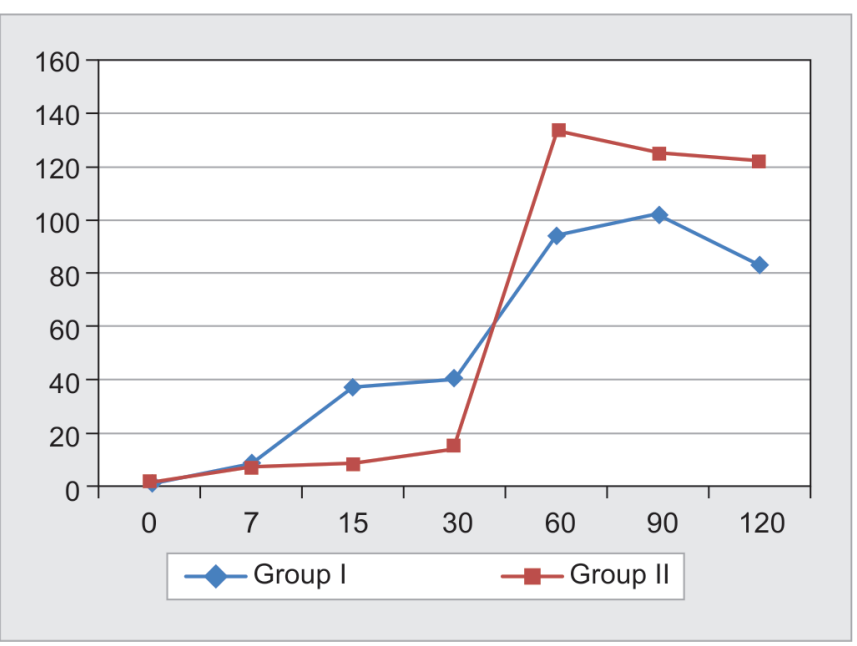

Graph 2: Level of osteocalcin (OCN) in both groups

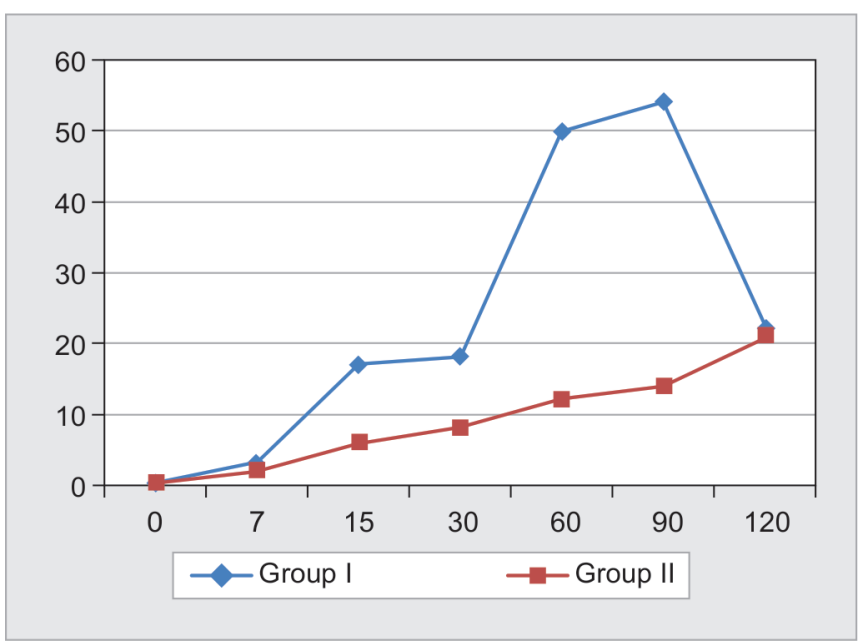

Graph 4: Level of PTH in both groups

osseointegration in animals. ${ }^{7,8}$ This study assessed the effect of immediately loaded implants on bone markers such as TGF- $\alpha$, OCN, OPN and PTH. Patients were classified into 2 groups. In group I, the immediate loaded dental implant was given in 30 patients and group II, 30 patients received dental implants only, and the prosthetic part was given after 4 months. 


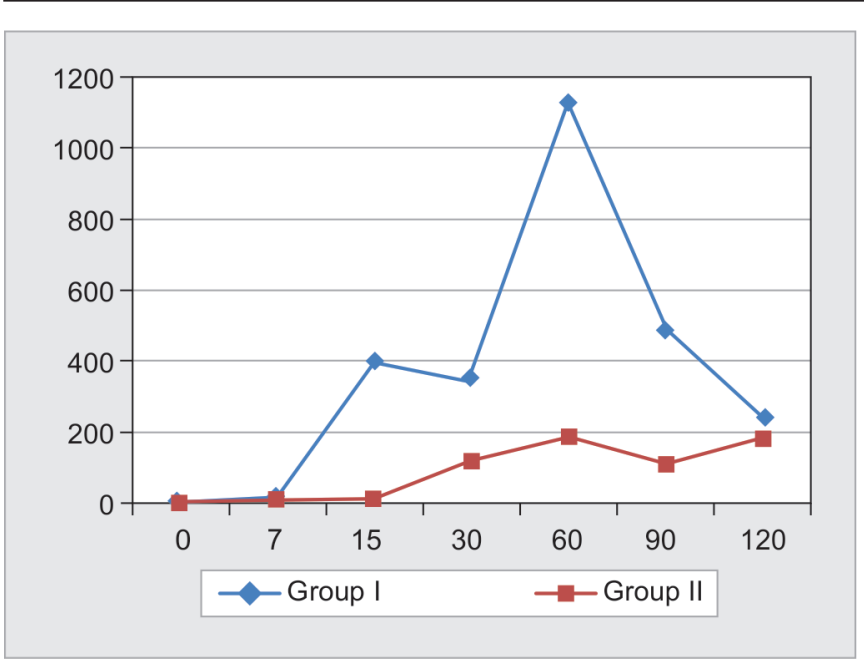

Graph 5: Level of OPG in both groups

In the present study, peri-implant sulcus depth was assessed in both the groups. We found that it was non- significant in both groups measured at 1, 2, 3 and 4 months. This shows that in both immediate loaded dental implants and non-loaded dental implant groups, there was no significant difference in values of sulcus depth. Similarly modified bleeding on probing index was assessed in both the groups. Group II had higher values as compared to group I measured at 1, 2 and 3 months. However, at 4 months, the values were almost similar. Though there was a difference in BOP values, the difference was nonsignificant $(p>0.05)$. This depicts that in both immediate loaded dental implant and non-loaded dental implants, there is a slight difference in BOP index. Bhardwaj et al. ${ }^{9}$ assessed sulcus bleeding index, papilla index and probing pocket depth in immediate loaded dental implants in single missing tooth found that at baseline the mean crestal bone loss was $0.25 \mathrm{~mm}$ which increased $0.88 \mathrm{~mm}$ after 9 months. Similarly, PPD found to be the same at 3 weeks and after 9 months. This showed that there was non-significant bone loss and probing pocket depth in immediate loaded dental implants.

Hartog et al. ${ }^{10}$ in their study compared immediate loaded dental implants placed in a maxillary anterior esthetic zone with conventional loaded dental implants. Bleeding index and probing pocket depth was nonsignificant in both the groups $(p>0.05)$ calculated after 6 and 18 months. However, our results are in contrast to the study done by Aspinall et al. ${ }^{11}$ In their study, the authors advocated delayed loading of dental implants. They suggested that there should be at least 3 to 6 months healing period after dental implant insertion and placement of prosthetic parts. They used Mombelli's bleeding index and found 0 value at 1, 3, 6, 9 and 12 months after prosthetic part placement. Similarly, mean probing depth was $2.1 \mathrm{~mm}$ throughout the recall visits.
Transforming growth factor $\alpha$ (TGF- $\alpha$ ) is proteinaceous in nature, similar to epidermal growth factor (EGF) structurally. Vandamme et al. ${ }^{12}$ in their study found that in immediate loaded dental implants osseointegration occur rapidly and the old bone gets replaced by new bone more effectively. This may be because of the release of bone markers in group I. Berghlund et al. ${ }^{13}$ in their study suggested that a fibrin-rich matrix is laid down by fibrins in initial phases of osseointegration. This forms a background for the new bone formation. Thus TGF- $\alpha$ determines future bone formation. Usmani et al..$^{14}$ in their study assessed TGF- $\alpha$ role in endochondral ossification confirmed that it has major role in angiogenesis and production of matrix metalloproteinase 9 and 14. We observed that TGF- $\alpha$ elevated quickly in initial stages after implant insertion and after reaching to its highest level, it falls simultaneously.

Nilsson et al. ${ }^{15}$ in their study on mice suggested that OCN determines binding of calcium ions to the extracellular matrix. It plays major role in mineralization of extracellular matrix. The level of OCN increases within a few days after loading of dental implants as seen in group I as compared to group II. Sato et al. ${ }^{16}$ in their study on dogs mandible observed that the level of OCN elevates significantly in immediately loaded dental implants. Similarly, OPN level found to be elevated more in group I as compared to group II. This suggests that in immediate loaded dental implants, it plays a vital role in osseointegration.

The level of PTH was altered slowly in both groups. It was found that after 2 months there was an increase in PTH level in both groups. However, the value was more in group I as compared to group II. After that, there was a downfall in group I and it reaches almost at the same level as in group II. This suggests that it affects the level of serum calcium and phosphorus. It has been found that because of the presence of receptors on the membranes of osteoblasts cells, initially there is a bone deposition. Recent studies ${ }^{17,18}$ have suggested that cumulative increase of OPG and PTH is efficient in inhibiting PTH-induced bone resorption which subsequently results in bone deposition in loaded implants. The present study also revealed a gradual increase in OPG in loaded dental implants. This might be linked to the fact that OPG reduces the PTH receptor activity in osteoclasts, a potential therapeutic model for severe osteoporosis.

\section{CONCLUSION}

The assessment of bone markers plays an important role in the determination of the success of dental implants. Bone markers such as TNF- $\alpha$, OCN, OPN, OPG, and PTH 
level was elevated in group I as compared to group II. Both groups revealed non-significant difference in modified bleeding on probing depth and peri-implant sulcus depth. However, large-scale studies are required in the future to substantiate the results obtained in thepresent study.

\section{REFERENCES}

1. Turkyilmaz I. Clinical and radiological results of patients treated with two loading protocols for mandibular overdentures on Brånemark implants. J Clin Periodontol 2006; 33:233-238.

2. Chiapasco M, Gatti C. Implant-retained mandibular overdentures with immediate loading: a 3- to 8-year prospective study on 328 implants. Clinical implant dentistry and related res 2003; 5(1):29-38.

3. Ostman PO. Immediate/early loading of dental implants. Clinical documentation and presentation of a treatment concept. Periodontol 2008; 47(1):90-112.

4. Schliephake H, Rödiger M, Phillips K, McGlumphy EA, Chacon GE, Larsen P. Early loading of surface modified implants in the posterior mandible- 5 year results of an open prospective non-controlled study. J Clin Periodontol 2012; 39(2):188-195.

5. Brånemark PI, Engstrand P, Ohrnell LO, Gröndahl K, Nilsson P, Hagberg K, et al. Brånemark Novum: A new treatment concept for rehabilitation of the edentulous mandible. Preliminary results from a prospective clinical follow-up study. Clin Implant Dent Relat Res 1999;1:2-16.

6. Ogawa T, Possemiers T, Zhang X, Naert I, Chaudhari A, Sasaki $\mathrm{K}$, et al. Influence of whole-body vibration time on peri-implant bone healing: A histomorphometrical animal study. J Clin Periodontol 2011;38(2):180-185.

7. Valenta A, Roschger P, Fratzl-Zelman N, Kostenuik PJ, Dunstan CR, Fratzl P, et al. Combined treatment with PTH (1-34) and OPG increases bone volume and uniformity of mineralization in aged ovariectomized rats. Bone 2005;37(11):87-95.

8. EsakiD, Matsushita Y, Ayukawa Y, Sakai N, Sawae Y, Koyano K. Relationship between magnitude of immediate loading and peri-implant osteogenesis in dogs. Clin Oral Implants Res 2012; 23:1290-1296.
9. Bhardwaj I, Bhushan A, Baiju CS, Bali S, Joshi V. Evaluation of peri-implant soft tissue and bone levels around early loaded implant in restoring single missing tooth: A clinicoradiographic study. J Indian Soc Periodontol. 2016; 20(1): 36-41.

10. Den Hartog L, Raghoebar GM, Stellingsma K, Vissink A, Meijer HJ. Immediate non-occlusal loading of single implants in the aesthetic zone: a randomized clinical trial. Journal of clinical periodontology. 2011; 38(2):186-194.

11. Aspalli S, Prebha M, Guttiganur N, Gaddale R. Delayed loading and peri-implant evaluation of dental implants: Keys to higher success in lesser dense bone. Journal of Dental Implants. 2015; 5(1):69.

12. Vandamme K, Naert I, Geris L, Vander Sloten J, Puers R, Duyck J. The effect of micro-motion on the tissue response around immediately loaded roughened titanium implants in the rabbit. Eur J Oral Sci 2007;115(1):21-29.

13. Berglundh T, Abrahamsson I, Lang NP, Lindhe J. De novo alveolar bone formation adjacent to endosseous implants. Clin Oral Implants Res 2003;14(3):251-262.

14. Usmani SE, Pest MA, Kim G, Ohora SN, Qin L, Beier F. Transforming growth factor alpha controls the transition from hypertrophic cartilage to bone during endochondrial bone growth. Bone 2012;51(1):131-141.

15. Nilsson SK, Dooner MS, Weier HU, Frenkel B, Lian JB, Stein GS, et al. Cells capable of bone production engraft from whole bone marrow transplants in nonablated mice. J Exp Med 1999; 15:729-734.

16. Sato R, Matsuzaka K, Kokubu E, Inoue T. Immediate loading after implant placement following tooth extraction upregulates cellular activity in the dog mandible. Clin Oral Implants Res 2011;22(12):1372-1378.

17. Kostenuik PJ, Capparelli C, Morony S, Adamu S, Shimamoto G, Shen V, et al. OPG and PTH-(1-34) have additive effects on bone density and mechanical strength in osteopenic ovariectomized rats. Endocrinology 2001;142(10):42954304 .

18. Pierroz DD, Bonnet N, Baldock PA, Ominsky MS, Stolina M, Kostenuik PJ, et al. Are osteoclasts needed for the bone anabolic response to parathyroid hormone? A study of intermittent parathyroid hormone with denosumab or alendronate in knock-in mice expressing humanized RANKL. J Biol Chem 2010;285(36):28164-28173. 